\title{
Non-coding rRNA-mediated preferential killing in cancer cells is enhanced by suppression of autophagy in non-transformed counterpart
}

\author{
CJ Hwang ${ }^{1}$, JR Fields ${ }^{1}$ and Y-H Shiao, ${ }^{* 1}$
}

Interest to anticancer agents targeting $r R N A$ biogenesis is growing. Cis-non-coding rRNAs, alternative to primary rRNA, have been shown to regulate $r R N A$ biogenesis. We have recently detected bidirectional non-coding rRNAs that carry ribozyme-like properties. Anti-antisense oligonucleotides complementary to antisense non-coding rRNAs markedly stabilized the bidirectional transcripts and induced cell death in mouse lung cells. Here, we demonstrated that the same oligonucleotide killed mouse lungcancer cells preferentially, compared with non-cancer sister lines, suggesting its potential utility for cancer treatment. A human version of anti-antisense oligonucleotide, complementary to an rDNA intergenic site, mediated apoptosis primarily in cancer cells. Autophagic activation was largely undifferentiable between the anti-antisense and other oligonucleotides and accounted for the undesired cytotoxicity in non-cancer cells. Co-treatment with chloroquine, an autophagy inhibitor, reduced cytotoxicity in the non-cancer cells, but retained the anti-antisense-mediated killings in cancer cells. Furthermore, the anti-antisense oligonucleotide stabilized bidirectional non-coding rRNAs predominantly in human cancer cells and perturbed $r R N A$ biogenesis. Contributions of non-coding rRNAs to cell death were proven by transfection of in -vitro-synthesized transcripts. Taken together, cancer/non-cancer cells respond differently to stabilization of non-coding rRNAs, and such differential responses provide a window of opportunity to enhance anticancer efficacy.

Cell Death and Disease (2011) 2, e239; doi:10.1038/cddis.2011.110; published online 8 December 2011

Subject Category: Cancer

Transcription of the rDNA, a tandemly repeated gene and highly conserved across unicellular and multicellular organisms, ${ }^{1}$ is coordinated by many proteins, including oncogenes and tumor suppressors. ${ }^{2,3}$ Phosphorylation of several transcription factors, such as UBF, TIF-IA, and TIF-IB/SL1, by kinases in EGFR signaling and mTOR-related pathways is essential for the activation of $r D N A$ transcription. Proliferating cells elevate the demand of $r R N A$ production and subsequent ribosomal assembly to support growth and survival. Increase of nucleolar organizer region in size or number, representing actively transcribed $r R N A$ loci, has been a classical biomarker for tumor phenotype. ${ }^{4,5}$ The initial $47 S$ transcript undergoes serial steps of $r R N A$ processing to generate mature $18 S$, 5.8S, and $28 S$ rRNAs, starting with excision of the Leader sequence from the $5^{\prime}$ external transcribed spacer (ETS) at about +650 nucleotide in mice and at the +414 site in humans. $^{6,7}$ Many therapeutic drugs targeting $r R N A$ biogenesis, either at transcription or processing step, are common regimens for anticancer treatment. ${ }^{8}$ It has been shown that cisplatin suppresses $r R N A$ transcription by displacing UBF and RNA polymerase I to the periphery of the nucleolus ${ }^{9}$ and 5-fluorouracil disrupts $r R N A$ processing. ${ }^{10,11}$

The rRNA transcription is also regulated by nucleolarremodeling complex, which promotes gene silencing upon binding of an intergenic promoter rRNA of about 100-200 nucleotides in mouse fibroblast cells. ${ }^{12,13}$ Non-protein-coding RNAs, other than $r R N A$, are ubiquitously expressed in $60-70 \%$ of mammalian genomes and frequently regulate the transcription of nearby primary transcripts. ${ }^{14-16}$ Of these transcription-rich clusters, over $20 \%$ in humans and about $72 \%$ in mice are expressed as sense-antisense pairs. ${ }^{17-19}$ The levels of sense and antisense non-coding RNA may be concordant, that is, concurrently upregulated or downregulated, or discordant. ${ }^{16,19}$ In the rDNA gene, we detected bidirectional cis-non-coding rRNAs (nc-rRNAs) in mouse lung epithelial cells and they followed a feed-forward or concordant mechanism to elevate sense/antisense nc-rRNAs upon introduction of antisense oligonucleotides and to perturb rRNA biogenesis (Supplementary Figure S1a). Oligonucleotides complementary to antisense nc-rRNAs were more potent than those pairing with sense nc-rRNAs to trigger cell death in mouse lung cancer cells (Supplementary Figure S1b). As stabilization of nc-rRNAs is concurrent with perturbation of $r R N A$ biogenesis, this opens an opportunity to explore the potential of targeting nc-rRNAs for anticancer treatment. In this study, we applied antisense strategy to induce preferential cell death in mouse and human lung cancer cells. We determined the efficacy of cancer-selected

\footnotetext{
${ }^{1}$ Laboratory of Comparative Carcinogenesis, National Cancer Institute at Frederick, Frederick, MD, USA

${ }^{*}$ Corresponding author: Y-H Shiao, Laboratory of Comparative Carcinogenesis, National Cancer Institute at Frederick, Building 538, Room 205, NIH, West 7th Street, Frederick, MD 21702, USA. Tel: + 301846 1246; Fax: + 301846 5946; E-mail: shiaoy@mail.nih.gov

Keywords: non-coding RNA; rRNA; sense antisense; apoptosis; autophagy; anticancer

Abbreviations: nc-rRNA, noncoding rRNA; LNA, locked nucleic acid; RT-PCR, reverse transcription-polymerase chain reaction; ETS, external transcribed spacer; LDH, lactate dehydrogenase; NoRC, nucleolar remodeling complex; PBS-T, phosphate-buffered saline-Tween 20

Received 19.7.11; revised 06.9.11; accepted 19.9.11; Edited by A Stephanou
} 
cell elimination among antisense oligonucleotides complementary to various regions of sense and antisense nc-rRNAs. Mechanisms of oligonucleotide-mediated cytotoxicity, including apoptosis and autophagy, were examined in human lung cells. Their relevance to preferential killings in cancer cells and reduction of cytotoxicity in non-cancer counterpart are discussed.

\section{Results}

Potent cancer cell inhibition by oligonucleotides pairing with antisense nc-rRNAs. Two antisense oligonucleotides, LNA1-S and LNA1-AS (Figure 1a), complementary to mouse antisense and sense nc-rRNAs, respectively, were first applied to test whether stabilization of nc-rRNAs provides any advantage to inhibit lung cancer cells predominantly. The cell viability was compared among treatments and was significantly reduced by LNA1-S, relative to either iFect vehicle control or LNA1-AS, in E10/E9 and C10/A5 pairs of non-cancer/cancer sister lines (Figure 1b). The degree of reduction, calculated by percentage of decrease in formazan intensity, showed that the E9 and A5 cancer lines are more sensitive to LNA1-S-mediated cell inhibition than their non-cancer counterparts, E10 and C10. This presents the evidence that stabilization of nc-rRNAs by targeting antisense nc-rRNAs is a promising strategy for anticancer treatment.

To extend the anticancer potential of nc-rRNA stabilization to humans, the subsequent study focused on human lung cells. Among several oligonucleotides (Figure 1a), the $86 \mathrm{~S}$ complementary to the antisense nc-rRNA at -86 to -69 upstream from the transcription start site was mostly effective in reducing cell number in $\mathrm{H} 441$ and A549 cancer cells (Figure 2a and Supplementary Figure S2). Higher degree of reduction in cell density was appreciable in the $86 \mathrm{~S}$ treatment, compared with 84AS (Figure 2a). The 86S was therefore chosen for further characterization of mechanisms that lead to its superior cell inhibition in reference to the 84AS or a nonspecific scramble oligonucleotide control. The cytotoxic induction by $86 \mathrm{~S}$ relative to $84 \mathrm{AS}$ increased as a function of the dosing concentration (Figure $2 \mathrm{~b}$ ). The same trend was observed using the non-specific oligonucleotide. An approximately 2-fold stronger killing efficiency by the $86 \mathrm{~S}$ treatment over the 84AS was seen in H441 and A549 cancer lines at 30 and $40 \mathrm{nM}$. In contrast, similar killing efficiency between $86 \mathrm{~S}$ and 84AS treatment, also visualized in Figure 2a, was observed in non-cancer HPL regardless of dosing concentration, likely a result of background stress response to oligonucleotides. Undesired cytotoxicity in non-transformed HPL following $86 \mathrm{~S}$ or $84 \mathrm{AS}$ treatment prompted us to determine mechanisms of cell death that may lead to a better treatment strategy for killing human cancer cells predominantly.

Activations of apoptosis and autophagy and their relevance to anticancer efficacy. Small but significant increase of apoptosis was detected $24 \mathrm{~h}$ after oligonucleotide treatment, primarily in 86S-treated H441 and

a
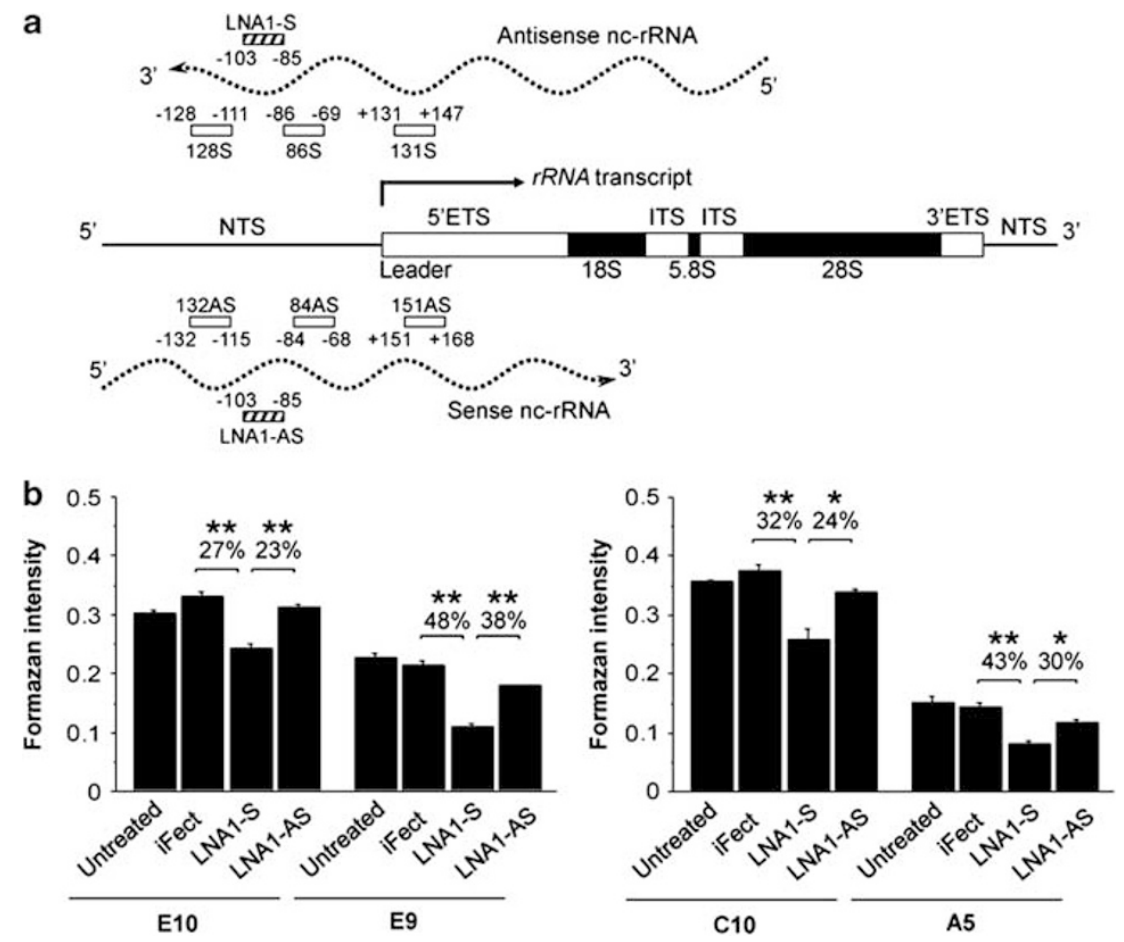

Figure 1 Oligonucleotides complementary to nc-rRNAs and preferential anticancer effects. (a) Oligonucleotide-targeting sites on sense and antisense nc-rRNAs. Hatched bars: Locked nucleic acid (LNA) gapmers for mouse lung cells; unfilled bars: regular oligonucleotides for human lung cells. (b) Cell viability of mouse lung cancer lines (A5 and E9) and corresponding non-cancer sister lines (C10 and E10), respectively, $24 \mathrm{~h}$ after transfection of $50 \mathrm{~nm}$ LNAs. ${ }^{*} P<0.05,{ }^{* \star} P<0.01$, compared with iFect vehicle control or LNA1-AS from triplicate samples. Error bars denote \pm standard error. NTS, nontranscribed spacer; ETS, external transcribed spacer; ITS, internal transcribed spacer 

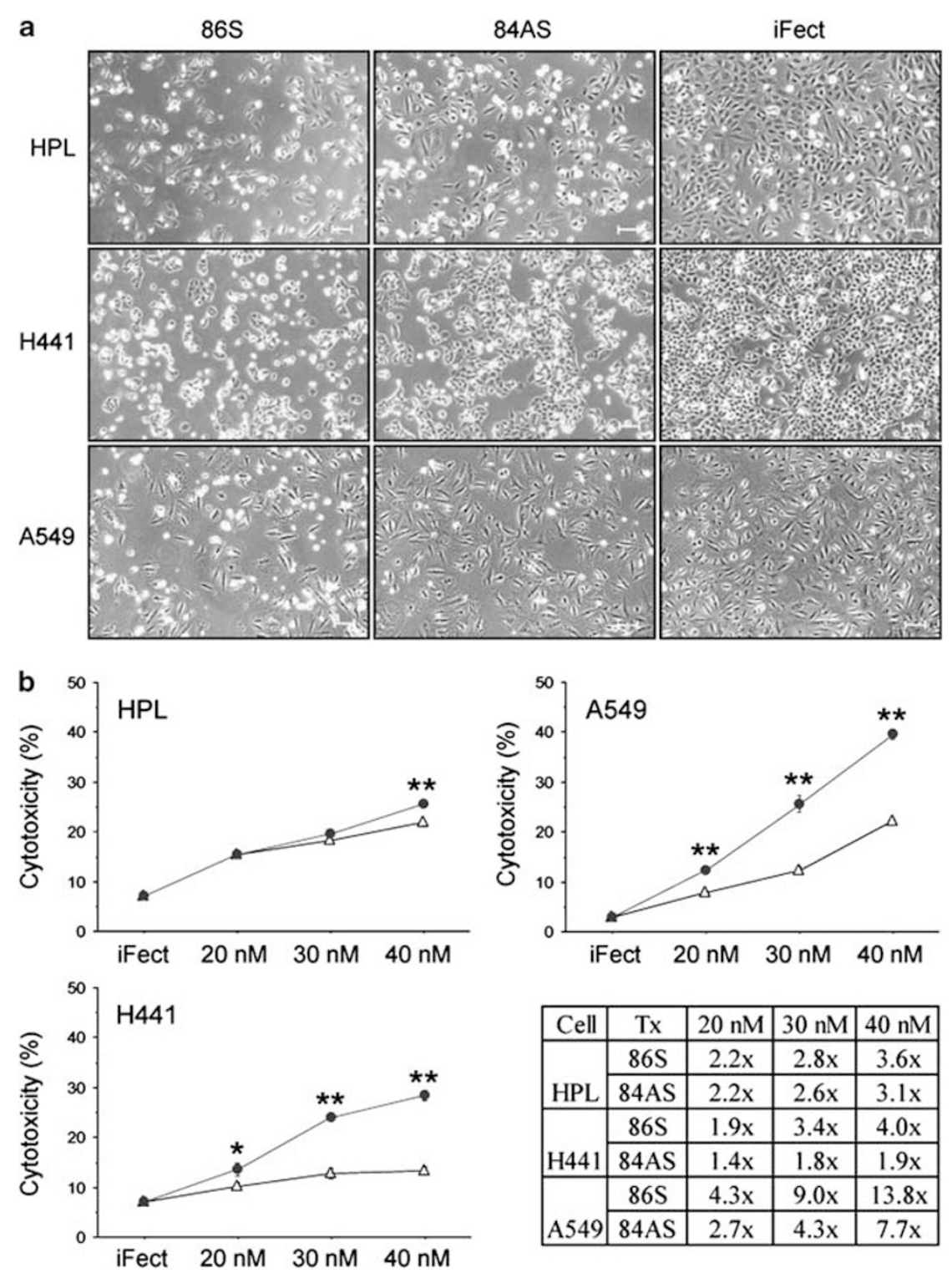

\begin{tabular}{|c|c|c|c|c|}
\hline Cell & Tx & $20 \mathrm{nM}$ & $30 \mathrm{nM}$ & $40 \mathrm{nM}$ \\
\hline & $86 \mathrm{~S}$ & $2.2 \mathrm{x}$ & $2.8 \mathrm{x}$ & $3.6 \mathrm{x}$ \\
\cline { 2 - 5 } $\mathrm{HPL}$ & $84 \mathrm{AS}$ & $2.2 \mathrm{x}$ & $2.6 \mathrm{x}$ & $3.1 \mathrm{x}$ \\
\hline & $86 \mathrm{~S}$ & $1.9 \mathrm{x}$ & $3.4 \mathrm{x}$ & $4.0 \mathrm{x}$ \\
\cline { 2 - 5 } $\mathrm{H} 441$ & $84 \mathrm{AS}$ & $1.4 \mathrm{x}$ & $1.8 \mathrm{x}$ & $1.9 \mathrm{x}$ \\
\hline & $86 \mathrm{~S}$ & $4.3 \mathrm{x}$ & $9.0 \mathrm{x}$ & $13.8 \mathrm{x}$ \\
\cline { 2 - 5 } $\mathrm{A} 549$ & $84 \mathrm{AS}$ & $2.7 \mathrm{x}$ & $4.3 \mathrm{x}$ & $7.7 \mathrm{x}$ \\
\hline
\end{tabular}

Figure 2 Selectivity of anticancer effects by oligonucleotides in human lung cells. (a) Microscopic images (scale bar, $100 \mu \mathrm{m}$ ) of non-transformed HPL and two cancer lines (H441 and A549) at $48 \mathrm{~h}$ after two transfections of $50 \mathrm{~nm}$ of $86 \mathrm{~S}, 84 \mathrm{AS}$, or iFect vehicle at 0 and $24 \mathrm{~h}$. Bright granules represent detached dead cells. (b) Quantitative assay for the percentage of detached cells relative to the total cell population $48 \mathrm{~h}$ after single transfection of $86 \mathrm{~S}$ (circle) or $84 \mathrm{AS}$ (triangle) at selected concentrations $\left({ }^{\star} P<0.05 ;{ }^{*} P<0.01\right.$; duplicate samples with triplicate measurements). Error bars denote \pm standard deviation. Background levels of cytotoxicity in iFect-treated controls were $7.1,7.1$, and $2.9 \%$ for HPL, H441, and A549, respectively. The killing efficiencies, calculated by fold changes of cytotoxicity in reference to corresponding iFect controls, were listed in the bottom right panel for $86 \mathrm{~S}$ and $84 \mathrm{AS}$ treatments $(\mathrm{Tx})$

A549 cancer lines, compared with non-specific scramble or 84AS oligonucleotide control (Figure 3). On the contrary, no elevation of apoptosis was detected in HPL non-cancer cells by the $86 \mathrm{~S}$ treatment at this time point. The second dosing of $40 \mathrm{~nm}$ oligonucleotides did not enhance the degree of apoptosis established at $24 \mathrm{~h}$ in cancer cells, but the fraction containing fragmented non-apoptotic cells was enlarged in the 86S-treated H441 cells (Figure 4). Other cell death mechanisms might be involved. The significant increase of apoptotic fraction in non-specific oligonucleotide- or 84AS-treated cells, compared with iFect vehicle control, in single $(24 \mathrm{~h})$ and double $(48 \mathrm{~h})$ treatments suggests a minor degree of cytotoxicity resulting from the presence of oligonucleotide per se. There were not any consensus changes across three phases of cell cycle at 24 and $48 \mathrm{~h}$ following the $86 \mathrm{~S}$ treatment (Supplementary Figures S3 and S4).

Apoptosis was further validated by upregulation of cleaved PARP and/or activated caspase 7, predominantly in 86S-treated cells (Figure 5a). H441 and A549 showed a steady apoptotic induction with increased levels of cleaved PARP and caspase 7 at $48 \mathrm{~h}$. The timing matched to the apoptotic phenotype representing internucleosomal DNA breaks (Figures 3 and 4). In contrast, HPL non-cancer cells followed a very weak apoptotic response to the $86 \mathrm{~S}$, evidenced by null 

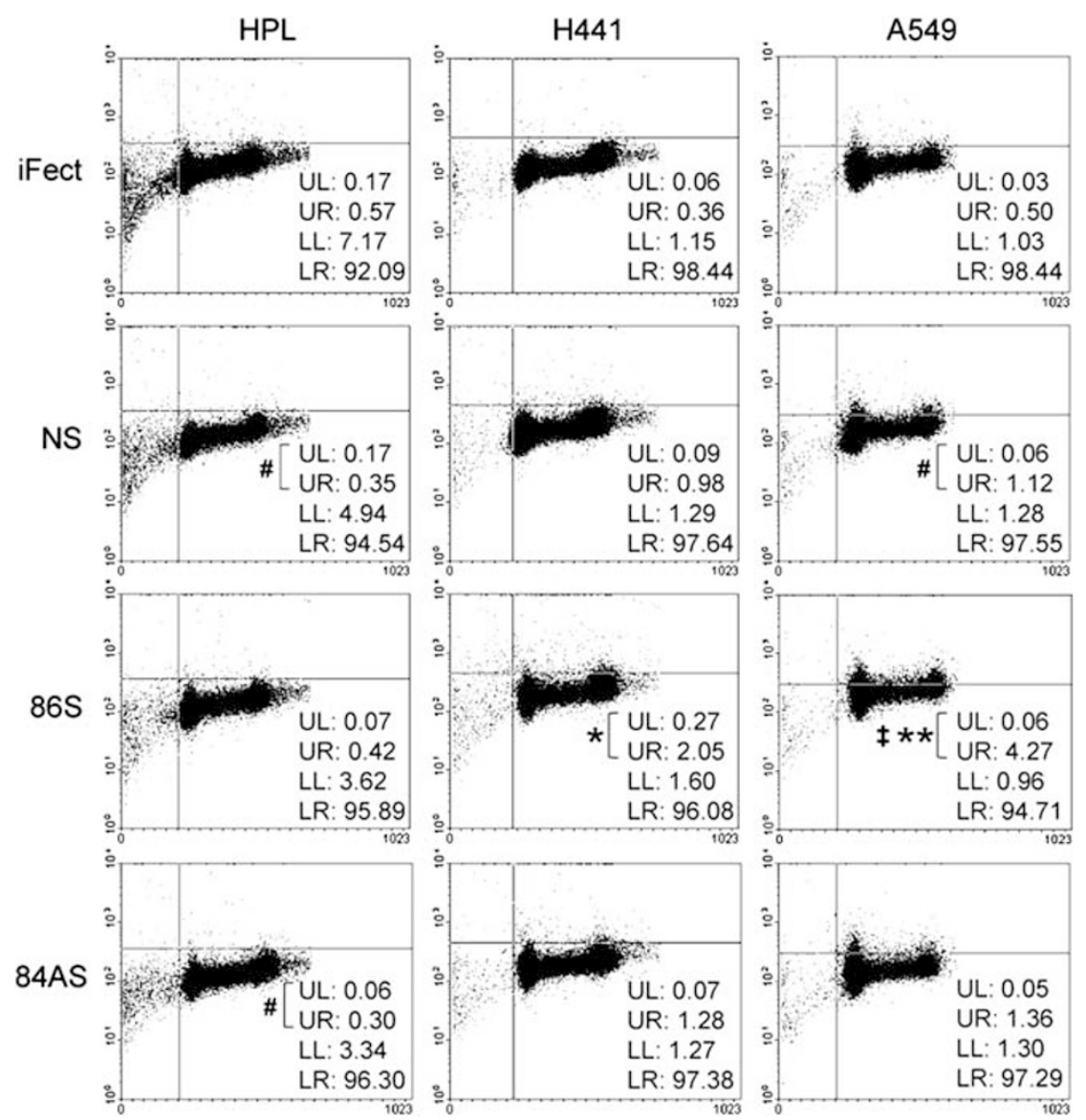

Figure 3 Induction of apoptosis $24 \mathrm{~h}$ after single transfection of $50 \mathrm{~nm}$ oligonucleotides. Comparisons of apoptotic fractions, upper left (UL) and upper right (UR), among duplicate samples from each oligonucleotide treatment. ${ }^{\sharp} P<0.05$, comparison of $84 \mathrm{AS}$ or NS with iFect control; ${ }^{\ddagger} P<0.05$, compared with $84 \mathrm{AS}$; ${ }^{\star} P<0.05$, ${ }^{* *} P<0.01$, compared with NS. Lower left (LL), fragmented/non-apoptotic fraction; lower right (LR), unaffected cells; NS, non-specific scramble oligonucleotide; $x$-axis, propidium iodide signal for DNA content; $y$-axis, fluorescein intensity in log scale for apoptosis

to minimal changes of the internucleosomal DNA breaks (Figures 3 and 4) and cleaved caspase 7 level (Figure 5a) at 24 and $48 \mathrm{~h}$. This suggests that apoptosis is not a major contributor for the undesired cytotoxicity in HPL, shown in Figure 2b. Also, changes of PARP levels in HPL did not correlate with internucleosomal DNA breaks, raising the possibility that PARP is not involved in apoptosis in non-transformed cells. The differential response to apoptosis between cancer and non-cancer cells further supports that cancer-selected cell destruction may be obtained through apoptotic activation by targeting antisense nc-rRNAs.

In addition to apoptosis, conversion of LC3B-I to LC3B-II protein, indicative of autophagy, was observed in 86Streated cells (Figure 5a). The 84AS and/or non-specific oligonucleotides were also tested in some experiments and their apoptotic inductions were clearly less effective than the $86 \mathrm{~S}$ treatment; however, the autophagic responses were mostly undistinguishable among oligonucleotides. On the contrary, the timing of autophagic activation relative to vehicle control varied among cells, and therefore the 86S-mediated autophagy was subsequently classified into steady (occurrence at both 24 and $48 \mathrm{~h}$ ) and weak response (occurrence at $48 \mathrm{~h}$ only). HPL and A549 showed steady response, whereas $\mathrm{H} 441$ followed a late or weak autophagic activation. The autophagy was confirmed by the presence of autophagosomes (Figure 5b).

Since autophagy has been implicated in both cell killing and survival, ${ }^{20,21}$ we next determined if co-treatment of oligonucleotide with chloroquine, an autophagy inhibitor, would enhance or suppress overall cytotoxicity. As shown in Figure 6, suppression of oligonucleotide-induced cytotoxicity by chloroquine co-treatment was demonstrated in HPL and A549 cells. The degrees of inhibition, calculated by relative reduction of killing efficiency after chloroquine co-treatment, ranged from about $40 \%$ in $\mathrm{HPL}$ to over $50 \%$ in A549, supporting that $86 \mathrm{~S}$ and even non-specific oligonucleotide induce cytotoxicity largely by autophagy in these two cells. This is consistent with the steady autophagic response of HPL and A549 cells, measured by the conversion of LC3B-I to LC3B-II protein as described above (Figure 5a). In contrast, killing efficiencies of oligonucleotides in H441were not reduced by the co-treatment with chloroquine, concordant with its weak response to autophagic activation represented by little changes in LC3B-II/LC3B-I ratio in Figure $5 \mathrm{a}$. This implies that high dosing concentrations of oligonucleotide may 

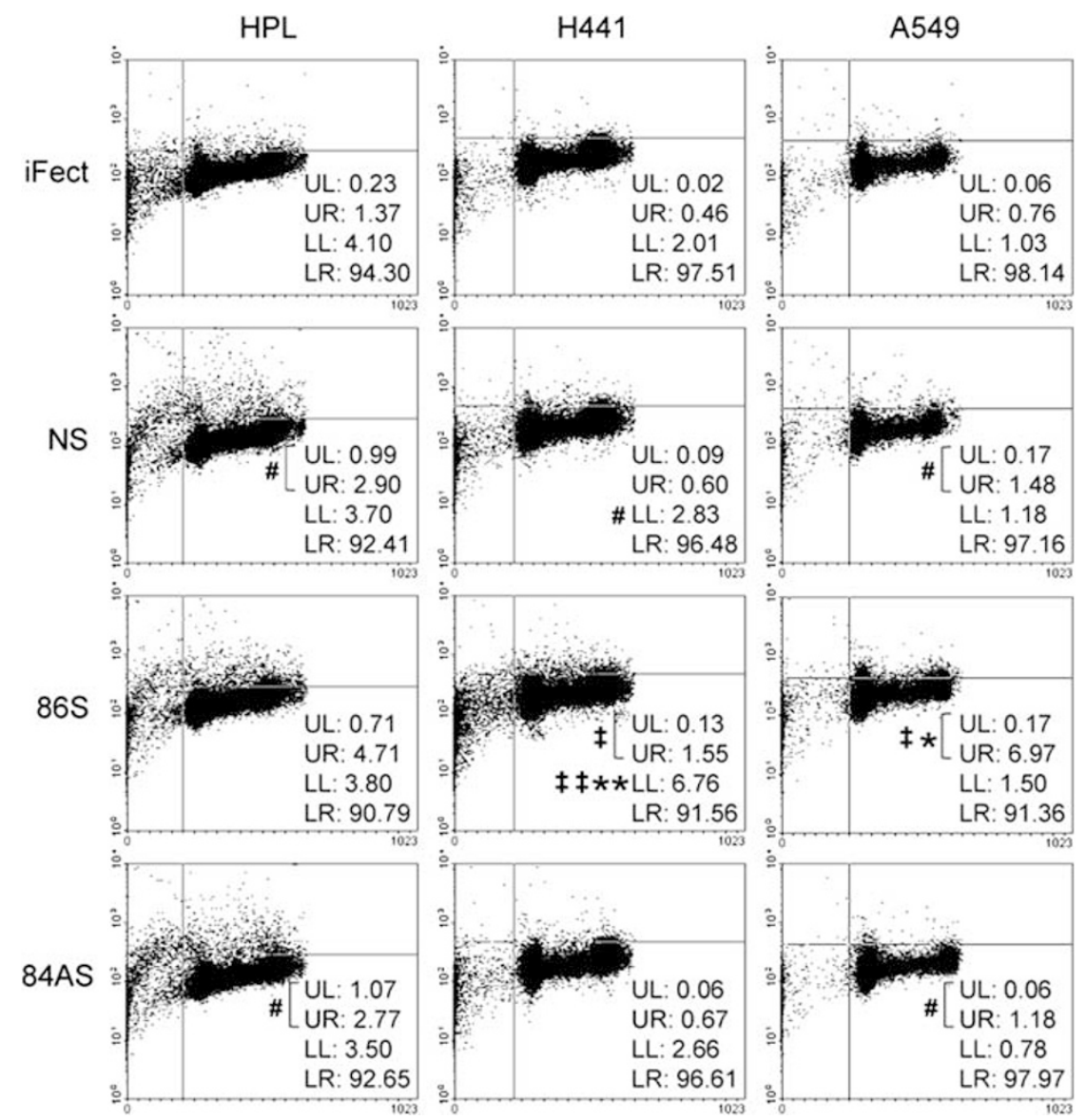

Figure 4 Induction of apoptosis after two transfections of $50 \mathrm{~nm}$ oligonucleotides at 0 and $24 \mathrm{~h}$. Comparisons of apoptotic fractions, upper left (UL) and upper right (UR), among duplicate samples from each oligonucleotide treatment. ${ }^{\sharp} P<0.05$, comparison of $84 \mathrm{AS}$ or NS with iFect vehicle control; ${ }^{\ddagger} P<0.05$, ${ }^{\ddagger \ddagger} P<0.01$, compared with 84AS; ${ }^{\star} P<0.05,{ }^{\star \star} P<0.01$, compared with NS. NS, nonspecific scramble oligonucleotide; $x$-axis, propidium iodide signal for DNA content; $y$-axis, fluorescein intensity in log scale for apoptosis
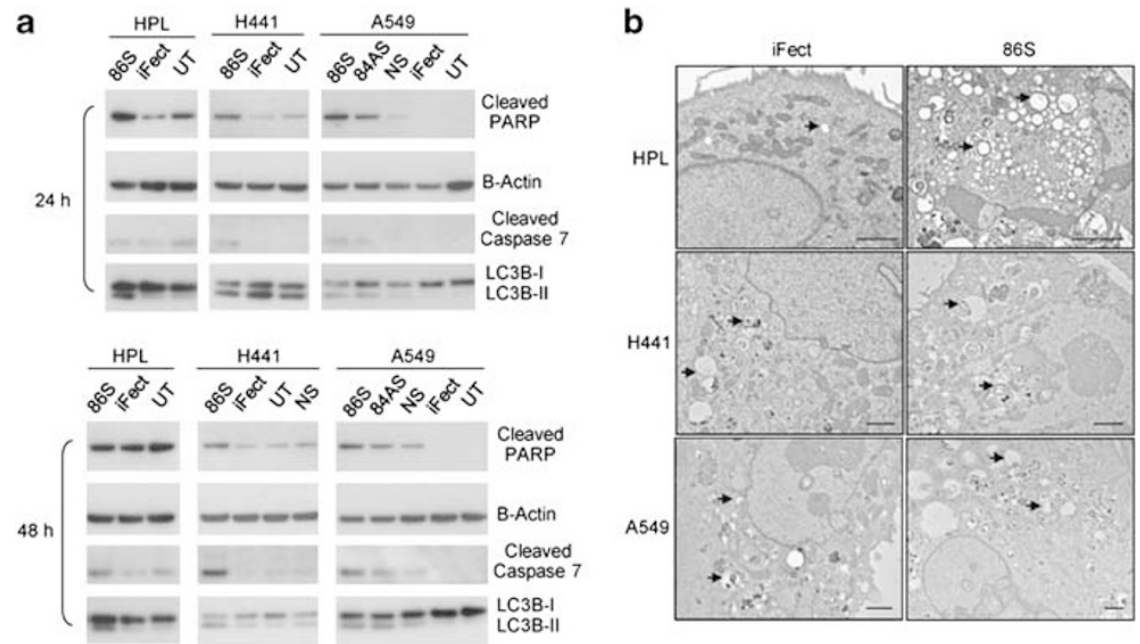

Figure 5 Activation of apoptotic and autophagic pathways by the 86S. (a) Western blot analyses of apoptotic (cleaved PARP and cleaved caspase 7) as well as autophagic (conversion of LC3B-I to LC3B-II) markers in cells 24 or $48 \mathrm{~h}$ (2 transfections at 0 and $24 \mathrm{~h}$ ) after initial transfection of $50 \mathrm{~nm}$ oligonucleotides. Apoptotic induction was represented by higher levels of cleaved PARP and/or cleaved caspase 7 relative to the iFect vehicle and/or untreated (UT) controls. (b) The ultrastructural signature of autophagosomes (arrows) was revealed under transmission scanning microscope. Autophagosomes were also detected in controls that did not receive oligonucleotides. Images were taken after two transfections of $50 \mathrm{~nm}$ oligonucleotides at $0 \mathrm{~h}$ and $24 \mathrm{~h}$ (scale bar: $2 \mu \mathrm{m}$ ). NS, nonspecific scramble oligonucleotide 

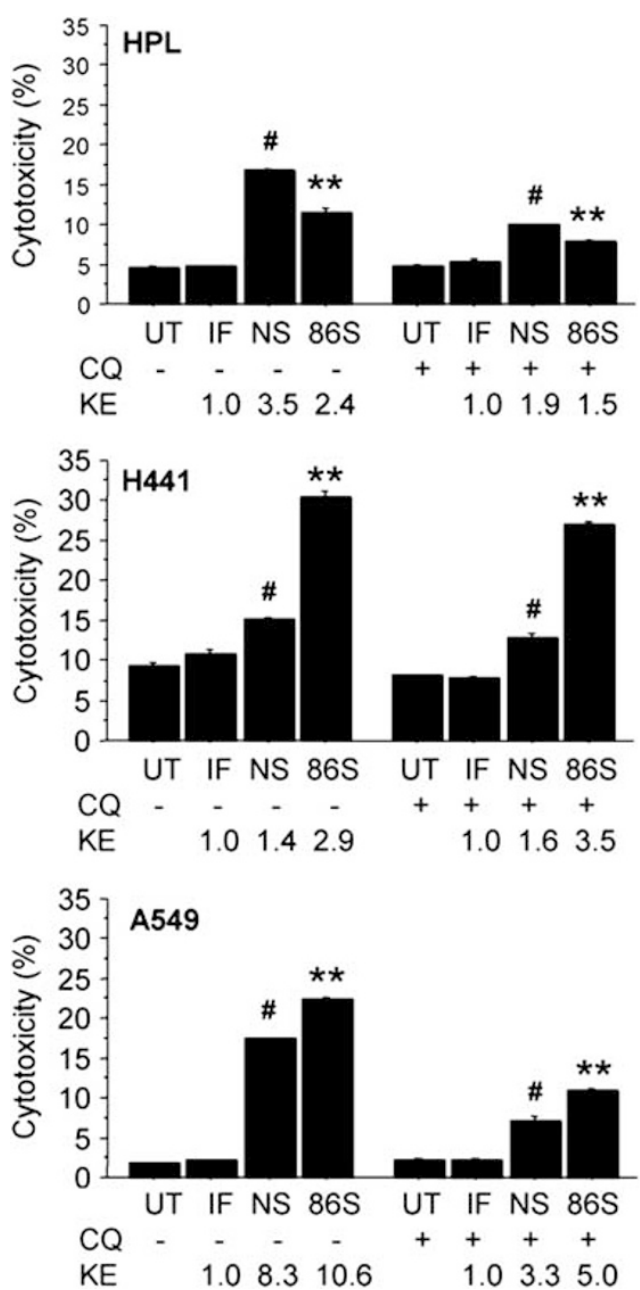

Figure 6 Differential suppression of oligonucleotide-induced cytotoxicity by chloroquine (CQ). Cell killing efficiency (KE) was calculated as ratio of averaged cytotoxicity in oligonucleotide-treated cells to the iFect vehicle control from duplicate samples in triplicate assays, measured $48 \mathrm{~h}$ after co-treatment of $25 \mu \mathrm{M}$ chloroquine with single transfection of $40 \mathrm{~nm}$ oligonucleotides. ${ }^{\#} P<0.05$, comparison of NS with iFect vehicle control; ${ }^{\star \star} P<0.01$, compared with NS. Error bars denote \pm standard error. UT, untreated; NS, nonspecific scramble oligonucleotide

be used along with chloroquine to maximize the anticancer efficacy and to minimize the cytotoxicity in normal cells.

Stabilization of nc-rRNAs by the $86 \mathrm{~S}$ oligonucleotide. The roles of nc-rRNAs in the above differential anticancer effects were explored next. A human sense nc-rRNA was reported early ${ }^{22}$ and the presence of an antisense nc-rRNA was confirmed by reverse transcription-polymerase chain reaction (RT-PCR) and sequencing here (nucleotides + 569 to +887 ). Search in GenBank Expressed Sequence Tag database also identified many cDNAs showing $>95 \%$ homology to the rDNA in antisense orientation. The basal levels of nc-rRNAs and serial $r R N A$ transcripts, that contain the Leader sequence, $5^{\prime} \mathrm{ETS}, 18 \mathrm{~S}$, and $28 \mathrm{~S}$ regions during $r R N A$ biogenesis ${ }^{7,23}$ were measured first to identify transcripts that may differentiate cancer from non-cancer cells. In comparison with non-transformed HPL, the levels of antisense nc-rRNAs and serial transcripts in rRNA biogenesis were in general higher in $\mathrm{H} 441$ and A549 cancer cells (Figure $7 \mathrm{a}$ ), providing evidence that cancer cells acquire elevated levels of these two groups of $r R N A$ species during tumorigenesis. The only exception is that the sense nc-rRNAs were higher in $\mathrm{H} 441$ but lower in A549, relative to HPL. Such variability of sense nc-rRNAs among cancer lines was reported before. ${ }^{22}$ Similar expression profiles between sparse and dense growth support that $r R N A$ biogenesis remains steady in cancer and non-cancer cells even at high degree of cell-cell contact.

The transcriptional profiles after treatments with $86 \mathrm{~S}$ and 84AS oligonucleotides were illustrated in Figure 7b. Stabilizations of both sense and antisense nc-rRNAs were detected, primarily in detached cells. The loss of viability for detached cells was validated by the retention of blue dye in trypan blue exclusion assay. The levels of upregulation for both nc-rRNAs were significantly higher in detached cancer cells induced by the $86 \mathrm{~S}$ treatment, compared with $84 \mathrm{AS}$. This provides the evidence that human bidirectional nc-rRNAs also follow a feed-forward mechanism, as seen in mouse lung cells, and are preferentially stabilized by the $86 \mathrm{~S}$ targeting antisense nc-rRNAs. No difference between 86S and 84AS treatment in HPL suggests that increases of nc-rRNAs in non-transformed cells are induced simply by the presence of oligonucleotide per se, which may account for the undesired cytotoxicity (Figures $2 \mathrm{~b}$ and 6 ). Strikingly, the levels of sense nc-rRNAs were upregulated 100- to 1000-fold in oligonucleotide-induced detached cancer cells, whereas only about 10 -fold accumulation of the transcript were observed in detached HPL cells. It is likely that slight accumulation of nc-rRNAs is detrimental to non-transformed cells, whereas cancer cells tolerate high levels of the transcripts. Elevations of sense and/or antisense nc-rRNAs were sporadically detected in adherent cells and the extent was much lower than detached cells, possibly a result of increased transcripts from dying cells, which were not yet detached.

Concurrent stabilization of nc-rRNAs (Figure 7b) and induction of cell death (Figure $2 \mathrm{~b}$ ) by the $86 \mathrm{~S}$ and $84 \mathrm{AS}$ treatments raised a possibility that sense and antisense nc-rRNAs may function as death mediators. Two lines of evidence support this hypothesis. First, perturbation of the $r R N A$ processing, represented by changes of serial $r R N A$ transcripts containing Leader sequence, $5^{\prime}$ ETS, $18 S$, and $28 S$ regions, was accompanied by upregulation of nc-rRNAs in 86S-and 84AS-induced detached cells (Figure 7b). Interference of $r R N A$ biogenesis is known to trigger cell destruction and is a common strategy in selecting anticancer agents. ${ }^{24-26}$ Second, striking accumulations of nc-rRNAs were observed in detached cells induced by nutrient starvation, namely, no culture media change for over 1 week (Figure $7 \mathrm{~b}$ ). The $r R N A$ biogenesis was also profoundly altered by the starvation treatment.

Induction of cell death directly by in -vitro-synthesized nc-rRNAs. To test the hypothesis that nc-rRNAs can mediate cell death directly, in-vitro-synthesized nc-rRNAs in sense and antisense orientations (Supplementary Table S1) were transfected into human lung cells. Initial trials of eight nc-rRNAs using transfection reagent as a control 
a
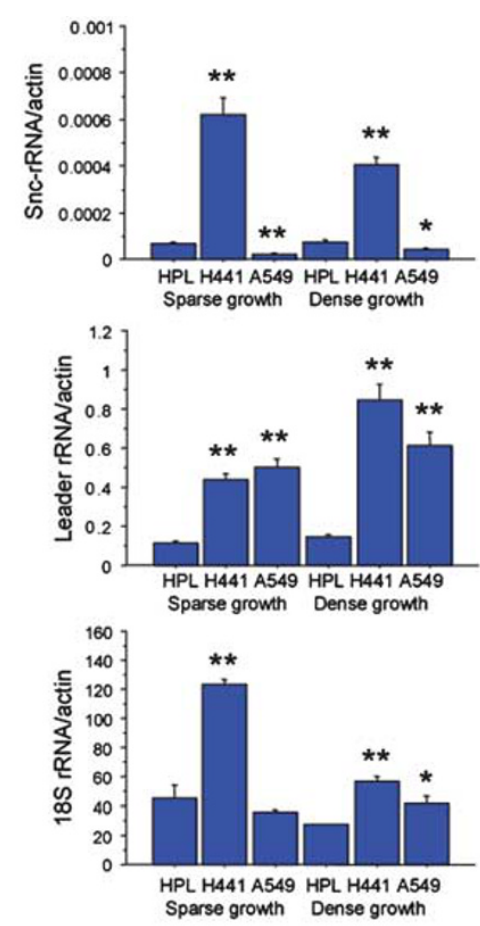
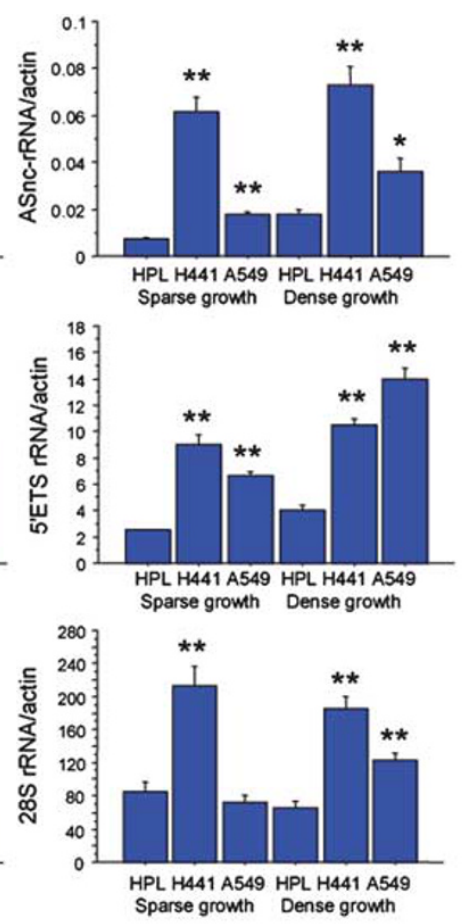

b

Adherent cells

Detached cells

\begin{tabular}{|c|c|c|c|c|c|c|}
\hline Transcript & Cell & $86 S$ & 84AS & $86 S$ & 84AS & Staned \\
\hline Sense & HPL & $+1.4, P=0.0611$ & +1.7. $P=0.0423$ & $+17.7 . P<0.0001$ & $+8.4, P=0.0201$ & $+13.2 . P=0.0012$ \\
\hline \multirow[t]{2}{*}{ nc-rRNA } & $\mathrm{H} 441$ & $+3.2^{\circ}: P=0.0070$ & +1.1. $P=0.5050$ & $+836.4^{\circ}: P<0.0001$ & $+140.9 . P<0.0001$ & $+450,0, P<0.0001$ \\
\hline & A549 & 177*:P<0.0001 & +71.9. $P<0.0001$ & $+1267.5^{\circ}: P<0.0001$ & $+319.8, P<0.0001$ & $+590.6 . P<0.0001$ \\
\hline \multirow{3}{*}{$\begin{array}{c}\text { Antisense } \\
\text { nc-rRNA }\end{array}$} & HPL & $+1.1^{\circ}, P=0.2859$ & $+18, P=0.0006$ & $+2.0, P=0.0003$ & 1.7. $P=0.0006$ & $+12.8, P<0.0001$ \\
\hline & $\mathrm{H} 441$ & $-1.6, P=0.0009$ & +1.1. $P=0.5869$ & $+12.5^{\circ}: P<0.0001$ & +3.6. $P<0.0001$ & -78.6. $P=0.0001$ \\
\hline & A549 & $+2.3^{*}: P=0.0007$ & $+1.6, P=0.0063$ & $+14.0 * \quad P<0.0001$ & $+3.8, P=0.0226$ & $+15.3 . P<0.0001$ \\
\hline \multirow{3}{*}{$\begin{array}{l}\text { Leader } \\
\text { rRNA }\end{array}$} & HPL & $+1.3 . P=0.0382$ & $+1.6, P=0,0028$ & $-1.5^{\circ}, P=0.0208$ & $-2.8, P=0.0023$ & $-2.0 . P=0.0050$ \\
\hline & $\mathrm{H} 441$ & $+1.3^{\circ}, P=0.1560$ & $-1.4, P=0.2687$ & $+2.8^{*}, P=0.0029$ & $-1.0 . P=0.9441$ & +5.6. $P=0.0006$ \\
\hline & A549 & $+2.6^{*}: P=0.0002$ & $+1.3, P=0.1994$ & $+2.1 * P=0.3290$ & $-3.3 . P=0.0045$ & $+1.1, P=0.7862$ \\
\hline \multirow{3}{*}{$\begin{array}{l}\text { 5'ETS } \\
\text { rRNA }\end{array}$} & HPL & +1.4. $P=0.0380$ & $+2.0 . P=0.0197$ & +3.7. $P=0.0003$ & $+3.9 . P=0.0001$ & $+5.7 . P<0.0001$ \\
\hline & $\mathrm{H} 441$ & +1.6. $P=0.1692$ & $+1.1, P=0.3158$ & $+5.9 * P=0.0005$ & $+2.7, P=0.0002$ & $+44.0, P=0.0001$ \\
\hline & A549 & $+3.2: P=0.0008$ & $+1.7, P=0.0819$ & $+12.7^{*}: P=0.0097$ & $+3.7 . P=0.0715$ & $+14.7, P=0.0023$ \\
\hline \multirow{3}{*}{$\begin{array}{l}18 S \\
\text { rRNA }\end{array}$} & HPL & +2.1. $P=0.0403$ & $+30, P=0.0019$ & $-2.8, P=0.0293$ & $-2.2, P=0.0509$ & +5.9. $P=0.0083$ \\
\hline & $\mathrm{H} 441$ & $+3.2 * P=0.0005$ & +1.2. $P=0.4197$ & $+3.3^{*}: P=0.0054$ & $+1.1 . P=0.7321$ & $+77.4 . p=0.0022$ \\
\hline & A549 & $+1.3, P=0.2055$ & $+1.0, P=0.9276$ & $+6.6^{*}: P=0.1366$ & $+1.1, P=0.8205$ & $+3.7 . P=0.0059$ \\
\hline \multirow{3}{*}{$\begin{array}{l}28 S \\
\text { rRNA }\end{array}$} & HPL & $+1.6, P=0.0674$ & $+1.3, P=0.3766$ & $+1.5, P=0.2759$ & $+1.0, P=0.9932$ & +9.3. $P=0.0027$ \\
\hline & $\mathrm{H} 441$ & $+2.0 * P=0.0015$ & $+1.2, P=0.2753$ & $+4.3 * P=0.0002$ & $+2.1 . P=0.0016$ & $+20.8, P<0.0001$ \\
\hline & A549 & $+4.1 . P=0,0083$ & $+4.5, P=0,0913$ & $+6.2: P=0.1133$ & $+1.7, P=0.3449$ & $+3.2 . P=0.0397$ \\
\hline
\end{tabular}

Figure 7 Levels of nc-rRNAs and $r R N A$ processing transcripts before and after oligonucleotide treatments. (a) The basal levels of nc-rRNAs and serial $r R N A$ transcripts representing a signature of $r R N A$ processing were quantified by RT-PCR at two growth conditions in untreated cells $\left({ }^{\star} P<0.05\right.$; ${ }^{*} P<0.01$; compared with HPL from duplicate samples). Error bars denote \pm standard error. (b) Heat map of fold changes of nc-rRNAs and serial transcripts during $r R N A$ biogenesis relative to adherent cells from iFect vehicle treatment after two transfections of $50 \mathrm{~nm}$ oligonucleotides at 0 and $24 \mathrm{~h}$. The choice of the iFect to obtain fold changes of transcripts avoided the differential effects of the vehicle itself on nc-rRNAs among cells, where upregulation (sense in A549 and antisense in HPL) and downregulation (antisense in A549) were observed (Data not shown). The iFect alone did not alter both nc-rRNAs in H441. Color denotes over 2-fold change and/or $P<0.05$ (red: upregulation; green: downregulation); ${ }^{*} P<0.05$, compared with 84AS in corresponding adherent and detached cells

detected elevation of cytotoxicity only for $7 S(-244$ to +203$)$ in the sense direction and two antisense transcripts, 2AS $(-1$ to -244$)$ and $8 A S(+203$ to -244$)$. The remaining in -vitro-transcribed nc-rRNAs in sense $(-244$ to $-1,-409$ to -248 , and -709 to -486$)$ and antisense $(-248$ to -409 and -486 to -709 ) orientations yielded cytotoxicity similar to the reagent control. The $7 \mathrm{~S}, 2 \mathrm{AS}$, and $8 \mathrm{AS}$ transcripts along with a control, $1 S$ (nucleotide -244 to -1 ), were chosen for further examination under two different dosing conditions (Figure 8). Significant increases of cytotoxicity were readily detectable following transfection of several nc-rRNA transcripts at $1 \mathrm{pmol}$ in HPL and A549. The high degree of cytotoxicity in HPL at 1 pmol recapitulates the susceptibility of HPL to cell detachment in the presence of 10 -fold, not 100 s to 1000 s, accumulation of nc-rRNAs (Figure 7b). Majority of cytotoxic response in $\mathrm{H} 441$ began to appear after transfection with $5 \mathrm{pmol}$ of the nc-rRNA transcripts. The requirement of higher dosing concentration to achieve significant cytotoxicity is consistent with the early observation that $\mathrm{H} 441$ maintains and tolerates abundant nc-rRNAs during basal 

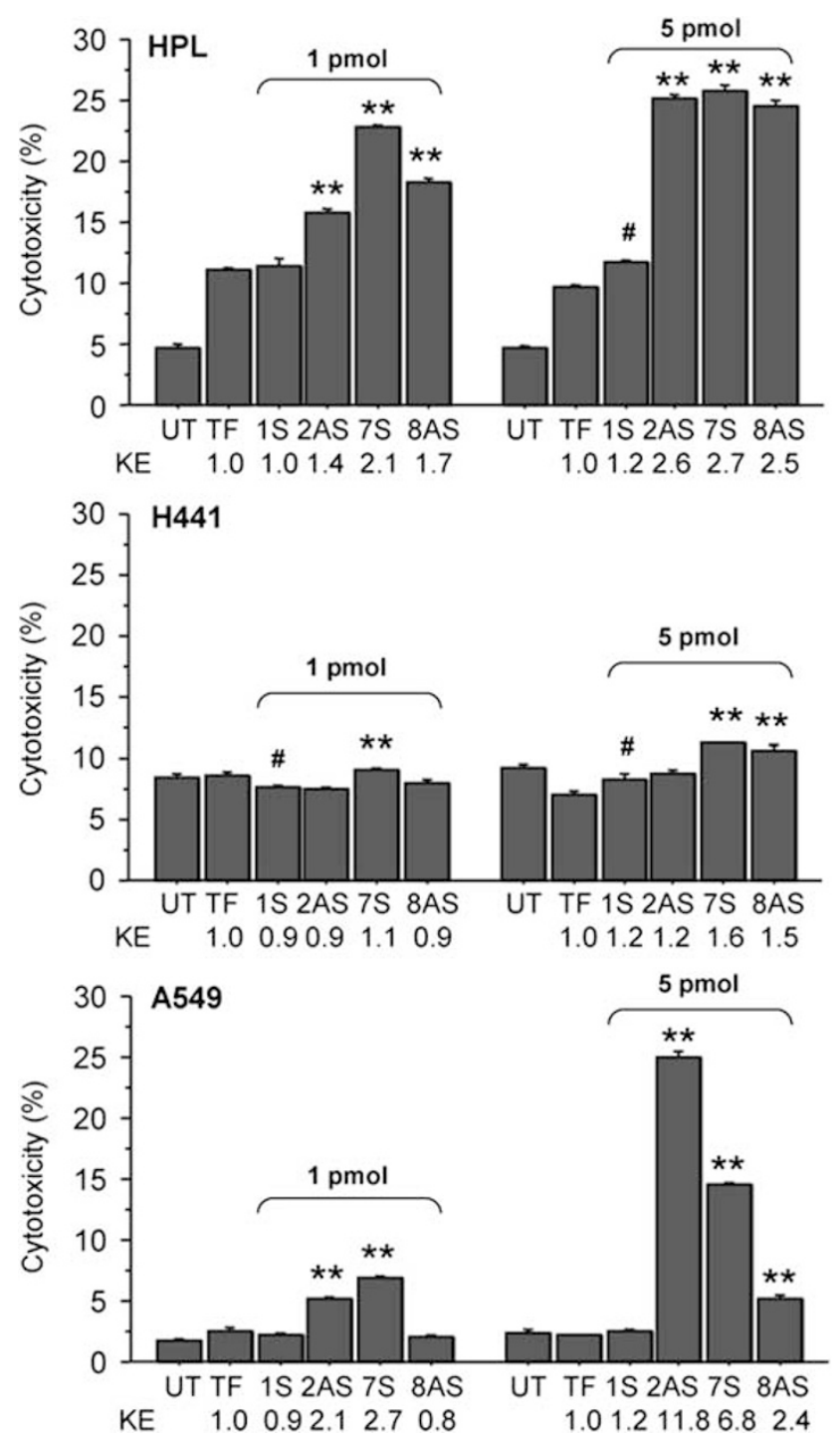

Figure 8 Direct induction of cytotoxicity by in vitro-synthesized nc-rRNAs. Cell killing efficiency (KE) was calculated from averaged cytotoxicity in cells $48 \mathrm{~h}$ after single transfection of selected nc-rRNA transcripts at 1 and $5 \mathrm{pmol}$ in $3 \mathrm{ml}$ cell culture in reference to the TransIT transfection (TF) vehicle control from duplicate samples in triplicate assays. ${ }^{\#} P<0.05$, comparison of $1 \mathrm{~S}$ with TF; ${ }^{*} P<0.01$, compared with the $1 S$ treatment. Error bars denote \pm standard error. UT, untreated

growth (Figure 7a). Killing efficiencies of both HPL and A549 were enhanced at the $5 \mathrm{pmol}$ dosing concentration as predicted, but the fold increases relative to corresponding treatments at $1 \mathrm{pmol}$ were greatly enhanced in A549 only. The fold changes were 1.3, 1.5, and 1.9 in HPL and 2.5, 3.0, and 5.6 in A549 for 7S, 8AS, and 2AS treatments, respectively. The degrees of changes in killing efficiency from $1 \mathrm{pmol}$ to $5 \mathrm{pmol}$ of $\mathrm{nc}$-rRNAs were relatively small in $\mathrm{HPL}$, implying that further increases of nc-rRNAs would still induce cytotoxicity predominantly in cancer cells. This preferential killing in A549 cancer cells over HPL noncancer line using in -vitro-synthesized nc-rRNA transcripts reminisces the anticancer effects that are induced by stabilization of nc-rRNAs using the $86 \mathrm{~S}$ oligonucleotide.

\section{Discussion}

In this study, we demonstrated that cis-bidirectional nc-rRNAs are potential targets for cancer-specific therapy. The $86 \mathrm{~S}$ oligonucleotide is more effective than the 84AS in the induction of apoptotic cell death in human lung cancer cells. This recapitulates the killing efficacy of targeting antisense nc-rRNA in mouse lung cancer cells. Although both oligonucleotides stabilized sense and antisense nc-rRNAs, the degree of upregulation was much higher and more steps of rRNA biogenesis were affected in cells committing to multiple death pathways following the $86 \mathrm{~S}$ treatment, compared with 84AS. This provides evidence that antisense nc-rRNA is a promising target for drug discovery. Its stabilization may trigger massive increase of complementary sense nc-rRNA, similar to types of concordant transcripts described before. ${ }^{16,19}$ Also, cancer cells, relative to non-cancer counterpart, are prone to the stabilization of nc-rRNAs, which are proven to be cell death mediators by transfection of synthetic transcripts, supporting the idea that formulation of drugs to stabilize antisense nc-rRNAs may preferentially eliminate cancer cells. Such regimen is further benefited by co-treatment with chloroquine to reduce $86 \mathrm{~S}$-mediated autophagy in HPL non-cancer cells. Although antisense nc-rRNAs are upregulated to a lesser extent than sense transcripts in response to the $86 \mathrm{~S}$ treatment, detection of cytotoxicity following direct introduction of synthetic antisense nc-rRNA suggests that the $86 \mathrm{~S}$ exerts dual killing effects by sense and antisense nc-rRNAs.

Previously, an intergenic nc-rRNA at around -142 to -43 nucleotide region, also known as promoter rRNA, was detected in mouse and human cells ${ }^{12,13}$ and was shown to form a stem-loop structure essential for the binding of TIP5, a component of nucleolar remodeling complex (NoRC). Disruption of the stem-loop structure or ectopic expression of the nc-rRNA transcript promoted migration of the NoRC from nucleolus to nucleoplasm and upregulated the level of the $47 \mathrm{~S}$ pre-rRNA that contains the Leader sequence. The $86 S$ in the current study is mapped to the stem-loop core region. The increase of the $47 S$ pre- $r R N A$ following the $86 S$ treatment might be initially interpreted as displacement of NoRC from the nucleolus by excessive sense nc-rRNA and subsequent relief of NoRC-mediated gene silencing, indicative of high demand for rRNA biogenesis. ${ }^{12}$ However, such a burst of $r R N A$ transcript level is concomitant with cell death, suggesting that the increase of the $47 S$ rRNA is a ramification of perturbation in the $r R N A$ processing. This assumption is supported by a report finding disruption of $r R N A$ processing in human cancer cells after expression of exogenous sense and antisense nc-rRNAs from the $5^{\prime} E T S$ region. ${ }^{27}$ The alteration in the rRNA processing is further revealed by the changes of other pre-rRNA intermediates that contain $5^{\prime} E T S, 18 S$, and $28 \mathrm{~S}$ regions. It is likely that level changes of serial pre-rRNA transcripts during processing in detached cancer cells is a result of duplex formation with upregulated antisense nc-rRNAs or competition with excess sense nc-rRNAs. The efficacy of cancer-selected killing by the $86 \mathrm{~S}$, better than 84AS, advocates that continuous screening for extensive regions of antisense nc-rRNAs with oligonucleotides may identify additional potent anticancer targets. Besides the strategy to upregulate nc-rRNAs by oligonucleotides, in 
theory, it is feasible to utilize the ribozymatic property of nc-rRNAs, demonstrated previously in mouse cells (Personal communication), for discovery of small-molecule ribozyme inhibitors.

Several agents known to interfere with $r R N A$ transcription and processing ${ }^{8}$ are first-line anticancer therapy, such as cisplatin for advanced non-small-cell lung carcinomas and 5-fluorouracil for colon cancers. ${ }^{28,29}$ The list of agents inhibiting various stages of $r R N A$ biogenesis continues to grow. $^{26,30,31}$ Furthermore, EGFR signaling and mTORrelated pathways have been linked to $r R N A$ biogenesis. ${ }^{2,3,8}$ It is reasonable to believe that tyrosine kinase inhibitors, ${ }^{32}$ for example, gefitinib and erlotinib, and mTOR antagonists, ${ }^{33}$ such as temsirolimus, may also suppress $r R N A$ biogenesis indirectly. The anti-nc-rRNA approach to selectively eliminate cancer cells, described in the current study, provides proof of principle to develop antisense oligonucleotides for anticancer treatment targeting $r R N A$ biogenesis. This strategy may be also applied to other antisense and sense non-coding transcripts, reported to be differentially expressed at genome scale in cancers. ${ }^{34}$

\begin{abstract}
Materials and Methods
Cell lines and culture. Non-transformed peripheral lung cells of BALB/C mouse origin, $\mathrm{C} 10$ and $\mathrm{E} 10$, and corresponding spontaneously transformed $\mathrm{A} 5$ and E9 sister lines, respectively, were obtained and cultured, as previously described. ${ }^{35}$ HPL1D, a non-transformed line derived from human peripheral lung epithelium, was obtained from Drs. T Takahashi and A Masuda and maintained in a standard medium, as described before, ${ }^{36}$ with some modifications to replace fungizone and fetal calf serum with $4 \mathrm{~mm}$ glutamine and $1 \%$ fetal bovine serum (Gemini BioProducts, West Sacramento, CA, USA). Human lung adenocarcinoma cell lines, A549 and H441, were purchased from American Type Culture Collection (Manassas, VA, USA) and were propagated routinely in RPMI 1640 media (Invitrogen, Carlsbad, CA, USA). To minimize the variation due to culture formulation, $\mathrm{H} 441$ and $\mathrm{A} 549$ were temporarily grown in the same media as the HPL throughout 24 or $48 \mathrm{~h}$ transfection with oligonucleotides.
\end{abstract}

RNA extraction, RT and PCR. Total RNA was extracted using RNeasy Mini RNA kit (Qiagen, Germantown, MD, USA), according to the manufacturer's protocol. Residual DNA was removed by recombinant DNase I and total RNA was purified and quantified, as previously described. ${ }^{22} \mathrm{RT}$ to generate CDNA was carried out at $50^{\circ} \mathrm{C}$ using the SuperScript III kit (Invitrogen), according to the manufacturer's instruction, and gene-specific primers (Supplementary Table S1). Six regions of human $r R N A$ gene, corresponding to serial transcripts that contain the Leader sequence, $5^{\prime} E T S, 18 \mathrm{~S}$, and $28 \mathrm{~S}$ regions in rRNA processing and putative nc-rRNAs in sense as well as antisense directions, were quantified in reference to beta-Actin internal control. Quantitative real-time PCR for all regions was performed in the Chromo4 System (Bio-Rad, Hercules, CA, USA). Each reaction of a total volume of $20 \mu \mathrm{l}$ contained $0.5 \mu \mathrm{M}$ gene-specific primer pairs (Supplementary Table S1), $1 \times$ SYBR Green PCR Mix (Qiagen), and $2 \mu$ of CDNA. PCR was carried out at $95^{\circ} \mathrm{C}$ for $15 \mathrm{~min}$, followed by $35-40$ cycles of $94^{\circ} \mathrm{C}$ for $15 \mathrm{~s}, 65^{\circ} \mathrm{C}$ for $20 \mathrm{~s}$, and $72{ }^{\circ} \mathrm{C}$ for $30 \mathrm{~s}$. Mouse transcripts were detected using the following primers and $55^{\circ} \mathrm{C}$ annealing temperature at PCR step. RT primers were gagacaaacctggaacg (for Leader and $5^{\prime}$ ETS $r R N A s$ ), acctatctccaggtccaatagg (for sense nc-rRNAs), polyT20 (for antisense nc-rRNAs), and gctgtagccgtattcatt (for the Gapdh internal control). The corresponding PCR primers for each region were gtggagagtcccga gtactt/ggggcaagacagttactgata (Leader sequence), acgtgttcacttggtcgt/acctcgacgct tacaagaaa (5'ETS), gcggtttctttcattgacc/acctatctccaggtccaatagg (sense nc-rRNAs), gcggtttcttcattgacc/ccttaaatcgaaagggtctctt (antisense nc-rRNAs), and cctggagaaa cctgccaagtat/gagtgggagttgctgttgaagtc (Gapdh). Ct (cycle at threshold) values were determined by the Opticon Monitor 3 software (Bio-Rad). Intensity was subsequently converted using the $2^{-C t}$ formula. Two RTs and a total of four PCRs were carried out for each of duplicate samples.
Transfection. HPL and H441 cells were seeded in six-well plates at $2 \times 10^{5}$ cells/well and A549 at $1 \times 10^{5}$ cells/well. Cells were transfected with oligonucleotides (Figure 1a and Supplementary Table S1) using RNAiFect kit (Qiagen) according to the manufacturer's instruction and following the formulation of $1: 6$ oligonucleotide $(\mu \mathrm{g})$ to RNAiFect reagent $(\mu \mathrm{l})$ ratio. The transfection efficiency was determined using the Label IT RNAi Delivery Control (Mirus, Madison, WI, USA) and was comparable among cell lines. For the co-treatment with chloroquine, $50 \mu \mathrm{l}$ of $1.575 \mathrm{~mm}$ chloroquine in $1 \times$ phosphate-buffered saline solution was added immediately after transfection, to constitute a $25 \mu \mathrm{m}$ final chloroquine concentration. In vitro-transcribed nc-rRNAs (1-5 pmol) were transfected in a six-well plate format using TransIT-mRNA Transfection kit (Mirus), according to the manufacturer's protocol.

Cell viability, cytotoxicity, apoptotic DNA break, and cell cycle analyses. Cell viability was quantified by CellTiter $96 \mathrm{AQ}$ one solution cell proliferation kit (Promega, Madison, WI, USA) converting a tetrazolium compound to formazan for cells cultured in a 96-well plate. The CytoTox 96 Non-Radioactive Cytotoxicity Assay kit (Promega) was used to measure lactate dehydrogenase $(\mathrm{LDH})$ release, indicative of cytotoxicity. In brief, cells were transfected with oligonucleotides in 6-well plates as aforementioned. Three $50 \mu \mathrm{l}$ aliquots of supernatant before and after direct addition of a $300 \mu \mathrm{l}$ of Triton X-100 $(9 \% \mathrm{v} / \mathrm{v}$ in water) lysis solution were transferred to $96-$ well plates at designated time points for each of duplicate samples. The intensity of formazan, produced from $\mathrm{LDH}$ reaction, was quantified at $492 \mathrm{~nm}$ after 30 -min incubation. The level of cytotoxicity was expressed as relative intensity of formazan in supernatant to that of total lysate. Apoptosis as a result of internucleosomal DNA breaks and cell cycle fractions were quantified using the Apo-BrdU kit (Phoenix Flow Systems, San Diego, CA, USA) according to manufacturer's manual. More than 10000 stained cells were sorted and counted by flow cytometry. WinMDI 2.8 (http:// www.cyto.purdue.edu/flowcyt/software.htm) and Cylchred (http://www.facslab. toxikologie.uni-mainz.de/engl.\%20Websites/Downloads-engl.jsp) software were used to calculate the fractions of apoptotic cells and 3 phases of cell cycle, respectively.

Transmission electron microscopy. In situ processing technique of cultured cells in 6-well plate for the transmission electron microscopy was described previously. ${ }^{37}$ Thin-sections $(90 \mathrm{~nm})$ were mounted on 150 mesh grids, stained in uranyl acetate and lead citrate, stabilized by carbon evaporation, and examined with an electron microscope (Hitachi, Tokyo, Japan) at $80 \mathrm{kV}$. Images were captured with a high resolution CCD camera (AMT, Danvers, MA, USA).

Western blot analysis. Cells seeded in 6-well plates were washed twice with phosphate-buffered saline (pH 7.4) and lysed with $100 \mu$ l CellLytic MT Mammalian Tissue/Lysis Extraction reagent (Sigma, St. Louis, MO, USA) with inclusion of $1 \times$ Complete Mini Protease Inhibitor Cocktail (Roche Applied Science, Mannheim, Germany). Protein concentration was measured using the BCA Protein Assay kit (Thermo Scientific, Wilmington, DE, USA). Proteins were resolved in $4-12 \%$ NOVEX NuPAGE Bis-Tris gel (Invitrogen) and electroblotted onto PVDF membranes (Bio-Rad) at $32 \mathrm{~V}$ for $1.5 \mathrm{~h}$. Membranes were blocked for $2 \mathrm{~h}$ at room temperature with $5 \%$ non-fat powder milk in $0.01 \%$ Tween 20/phosphate-buffered saline (PBS-T) solution and then probed with specific primary rabbit antibodies against cleaved PARP (1:500 dilution), cleaved caspase 7 (1:500), LC3BI and II $(1: 500)$, and beta-Actin $(1: 20000)$ overnight at $4{ }^{\circ} \mathrm{C}$. After multiple washes with PBS-T, blots were incubated at room temperature for $1.5 \mathrm{~h}$ with donkey anti-rabbit IgG secondary antibody conjugated with horseradish peroxidase (1:500 for PARP, caspase 7, and LC3B; $1: 1000$ for beta-Actin). After washes, blots were developed using a chemiluminescence ECL and ECL Plus kit (Amersham, Piscataway, $\mathrm{NJ}$, USA) for beta-Actin/LC3B and PARP/caspase 7, respectively, and were exposed to X-ray film (Amersham). Beta-Actin served as a loading control.

In vitro transcription. The templates for in vitro transcription were generated by PCR using primer pairs listed in Supplementary Table S1. Transcription was carried out at $37^{\circ} \mathrm{C}$ for $18 \mathrm{~h}$ using $0.5-1.0 \mathrm{pmol}$ DNA template and MEGAscript T7 kit (Applied Biosystems, Carlsbad, CA, USA) and the transcripts were subsequently purified with MEGAclear kit (Applied Biosystems) according to the manufacturer's instructions. The sizes and integrity of transcripts were verified in Tris-Urea polyacrylamide gel (Invitrogen).

Statistical analysis. Student's $t$-test was applied to determine the differences of cytotoxicity, apoptosis, cell cycle fraction, nc-rRNAs, and serial transcripts 
of $r R N A$ biogenesis among treatments of oligonucleotides or in vitro-transcribed nc-RNAs. The differences between comparisons were considered significant if $P$-values were $<0.05$.

\section{Conflict of Interest}

The authors declare no conflict of interest.

Acknowledgements. We would like to thank Kunio Nagashima and Adam Harned at Image Analysis Laboratory, SAIC-Frederick for transmission electron microscopy, Robin Steward at the Laboratory of Molecular Technology, SAICFrederick for dideoxy DNA sequencing, and Kathleen Noer and Guity Mohammadi at Center for Cancer Research-Frederick Flow Cytometry Core for the flow analysis. We also thank Udo Rudloff for critical reading of the manuscript. This research was supported in part by the Intramural Research Program of the $\mathrm{NIH}$, National Cancer Institute, Center for Cancer Research.

1. Long EO, Dawid IB. Repeated genes in eukaryotes. Ann Rev Biochem 1980; 49: 727-764

2. Ruggero D, Pandolfi PP. Does the ribosome translate cancer? Nat Rev Cancer 2003; 3 179-192.

3. White RJ. RNA polymerases I and III, non-coding RNAs and cancer. Trends Genet 2008; 24: $622-629$.

4. Derenzini M, Trere D, Pession A, Montanaro L, Sirri V, Ochs RL. Nucleolar function and size in cancer cells. Am J Pathol 1998; 152: 1291-1297.

5. Montanaro L, Trere D, Derenzini M. Nucleolus, ribosomes, and cancer. Am J Pathol 2008; 173: 301-310.

6. Gurney $\mathrm{Jr} \mathrm{T}$. Characterization of mouse $45 \mathrm{~S}$ ribosomal RNA subspecies suggests that the first processing cleavage occurs $600 \pm 100$ nucleotides from the $5^{\prime}$ end and the second $500 \pm$ nucleotides from the $3^{\prime} d$ end of a $13.9 \mathrm{~kb}$ precursor. Nucleic Acids Res 1985; 13: 4905-4919.

7. Eichler DC, Craig N. Processing of eukaryotic ribosomal RNA. Prog Nucleic Acid Res 1994; 49: 197-239.

8. Drygin D, Rice WG, Grummt I. The RNA polymerase I transcription machinery: an emerging target for the treatment of cancer. Annu Rev Pharmacol Toxicol 2010; 50 : 131-156

9. Jordan P, Carmo-Fonseca M. Cisplatin inhibits synthesis of ribosomal RNA in vivo. Nucleic Acids Res 1998; 26: 2831-2836.

10. Cohen MB, Glazer RI. Cytotoxicity and the inhibition of ribosomal RNA processing in human colon carcinoma cells. Mol Pharmacol 1985; 27: 308-313.

11. Ghoshal K, Jacob ST. Specific inhibition of pre-ribosomal RNA processing in extracts from the lymphosarcoma cells treated with 5-fluorouracil. Cancer Res 1994; 54: 632-636.

12. Mayer C, Schmitz KM, Li J, Grummt I, Santoro R. Intergenic transcripts regulate the epigenetic state of rRNA genes. Mol Cell 2006; 22: 351-361.

13. Mayer C, Neubert M, Grummt I. The structure of NoRC-associated RNA is crucial for targeting the chromatin remodeling complex NoRC to the nucleolus. EMBO Rep 2008; 9 : 774-780.

14. Okazaki Y, Furuno M, Kasukawa T, Adachi J, Bono H, Kondo S et al. Analysis of the mouse transcriptome based on functional annotation of 60770 full-length cDNAs. Nature 2002; 420: $563-573$

15. Ota T, Suzuki Y, Nishikawa T, Otsuki T, Sugiyama T, Irie R et al. Complete sequencing and characterization of 21243 full-length human cDNAs. Nat Genet 2004; 36: 40-45.

16. Faghini MA, Wahlestedt $C$. Regulatory roles of natural antisense transcripts. Nat Rev Mo Cell Biol 2009; 10: 637-643.

17. Yelin R, Dahary D, Sorek R, Levanon EY, Goldstein O, Shoshan A et al. Widespread occurrence of antisense transcription in the human genome. Nat Biotechnol 2003; 21 379-386.

18. Chen J, Sun M, Kent WJ, Huang X, Xie H, Wang W et al. Over $20 \%$ of human transcripts might form sense-antisense pairs. Nucleic Acids Res 2004; 32: 4812-4820.
19. Katayama S, Tomaru Y, Kasukawa T, Waki K, Nakanishi M, Nakamura M et al. Antisense transcription in the mammalian transcriptome. Science 2005; 309: 1564-1566.

20. Klionsky D, Abeliovich H, Agostinis P, Agrawal DK, Aliev G, Askew DS et al. Guidelines for the use and interpretation of assays for monitoring autophagy in higher eukaryotes. Autophagy 2008; 4: 151-175.

21. Livesey K, Tang D, Zeh HJ, Lotze M. Autophagy inhibition in combination cance treatment. Curr Opin Investig Drugs 2009; 10: 1269-1279.

22. Shiao YH, Lupascu ST, Gu YD, Kasprzak W, Hwang CJ, Fields JR et al. An intergenic noncoding rRNA correlated with expression of the rRNA and frequency of an rRNA single nucleotide polymorphism in lung cancer cells. PLoS One 2009; 4: e7505.

23. Henras AK, Soudet J, Gerus M, Lebaron S, Caizergues-Ferrer M, Mougin A et al The post-transcriptional steps of eukaryotic ribosome biogenesis. Cell Mol Life Sci 2008; 65: 2334-2359.

24. Holzel M, Orban M, Hochstatter J, Rohrmoser M, Harasim T, Malamoussi A et al. Defects in $18 \mathrm{~S}$ or $28 \mathrm{~S}$ rRNA processing activate the p53 pathway. $J$ Biol Chem 2010; 285 6364-6370.

25. Greenhalgh DA, Parish JH. Effect of 5-fluorouracil combination therapy on RNA processing in human colonic carcinoma cells. Br J Cancer 1990; 61: 415-419.

26. Burger $\mathrm{K}$, Muhl B, Harasim $\mathrm{T}$, Rohrmoser M, Malamoussi A, Orban $\mathrm{M}$ et al. Chemotherapeutic drugs inhibit ribosome biogenesis at various levels. $\mathrm{J}$ Biol Chem 2010; 285: 12416-12425.

27. Gagnon-Kugler T, Langlois F, Stefanovsky V, Lessard F, Moss T. Loss of human ribosomal gene CpG methylation enhances cryptic RNA polymerase II transcription and disrupts ribosomal RNA processing. Mol Cell 2009; 35: 414-425

28. Langer C, Soria JC. The role of anti-epidermal growth factor receptor and antivascular endothelial growth factor therapies in the treatment of non-small-cell lung cancer. Clin Lung Cancer 2010; 11: 82-90.

29. Lombardi L, Morelli F, Cinieri S, Santini D, Silvestris N, Fazio N et al. Adjuvant colon cancer chemotherapy: where we are and where we'll go. Cancer Treat Rev 2010; 36 (Suppl 3): S34-S41.

30. Drygin D, Siddiqui-Jain A, O'Brien S, Schwaebe M, Lin A, Bliesath $\mathrm{J}$ et al. Anticancer activity of CX-3543: a direct inhibitor of rRNA biogenesis. Cancer Res 2009; 69: 7653-7661.

31. Drygin $D$, Lin A, Bliesath J, Ho C, O'Brien S, Proffitt $C$ et al. Targeting RNA polymerase I with an oral small molecule CX-5461 inhibits ribosomal RNA synthesis and solid tumor growth. Cancer Res 2011; 71: 1418-1430.

32. Roberts PJ, Der CJ. Targeting the Raf-MEK-ERK mitogen-activated protein kinase cascade for the treatment of cancer. Oncogene 2007; 26: 3291-3310.

33. Gibbons JJ, Abraham RT, Yu K. Mammalian target of rapamycin: discovery of rapamycin reveals a signaling pathway important for normal and cancer cell growth. Semin Onco 2009; 36(Suppl 3): S3-S17.

34. Maruyama R, Shipitsin M, Choudhury S, Wu Z, Protopopov A, Yao J et al. Altered antisense-to-sense transcript ratios in breast cancer. Proc Natl Acad Sci USA 2010; www.Pnas.org/cgi/doi/10.1073/pnas.1010559107.

35. Sithanandam G, Smith GT, Fields JR, Fornwald LW, Anderson LM. Alternate paths from epidermal growth factor receptor to Akt in malignant versus nontransformed lung epithelia cells: ErbB3 versus Gab1. Am J Respir Cell Mol Biol 2005; 33: 490-499.

36. Masuda A, Kondo M, Saito T, Yatabe Y, Kobayashi T, Okamoto M et al. Establishment of human peripheral lung epithelial cell lines (HPL1) retaining differentiated characteristics and responsiveness to epidermal growth factor, hepatocyte growth factor, and transforming growth factor beta1. Cancer Res 1997; 57: 4898-4904.

37. Nagashima K, Zheng L, Parmiter D, Patri AK. Biological tissue and cell culture specimen preparation for TEM nanoparticle characterization. Methods Mol Biol 2011; 697 83-91.

Cell Death and Disease is an open-access journal published by Nature Publishing Group. This work is licensed under the Creative Commons Attribution-Noncommercial-No Derivative Works 3.0 Unported License. To view a copy of this license, visit http://creativecommons.org/licenses/by-nc-nd/3.0/

\section{Supplementary Information accompanies the paper on Cell Death and Disease website (http://www.nature.com/cddis)}

